\title{
DUPLA ESTRUTURA DA LINGUAGEM E DO CONHECIMENTO EM HEIDEGGER
}

\section{DOI: http://dx.doi.org/10.17058/barbaroi.v51i1.9859}

\author{
Cezar Luís Seibt
}

Universidade Federeal do Pará - UFPA - Brasil

\section{RESUMO}

O texto apresenta a linguagem e o conhecimento a partir de dois níveis: o nível dos entes e o nível do ser. Cotidianamente nos movemos numa compreensão da linguagem e do conhecimento baseada na entificação ou coisificação. Perdemos a conexão com o solo e as raízes pré-conceituais onde nossos empreendimentos se assentam. $\mathrm{O}$ pensamento de Martin Heidegger pode ser alerta para o perigo de que ao reduzir tudo a ente, a objeto, perdemos a capacidade de pensar, de manter conexão com o originário e, com isso, nos tornamos dependentes das coisas que criamos e com que lidamos cotidianamente. Vamos apresentar e distinguir esses dois níveis da linguagem e do conhecimento a partir do pensamento de Heidegger e da interpretação de Ernildo Stein.

Palavras-chave: linguagem, conhecimento, Heideggr.

\section{INTRODUÇÃO}

A reflexão sobre a linguagem aqui se liga ao problema do conhecimento, enfatizando uma dupla estrutura de manifestação e ocultamento. Na linguagem que utilizamos e na qual moramos opera um duplo movimento no qual as coisas são, ao mesmo tempo, manifestadas e ocultadas. Naquilo que dizemos, na realidade que expressamos, nos entes que afirmamos, também se recusa aquilo que é condição de possibilidade da manifestação dessa realidade, desses entes. É a compreensão do ser, o sentido do ser, como escreve Heidegger (1998) que se oculta, se recusa e é esquecido. O mesmo se passa no conhecimento, pois o que conhecemos oculta o horizonte que abre e torna possível o conhecimento das coisas enquanto estas ou aquelas.

$\mathrm{Na}$ vida cotidiana operamos no nível dos entes, das coisas, das representações. Este também é o nível em que fazemos ciência. Heidegger, com seu pensar, realizar um movimento através do qual pretende um retorno para as condições prévias, para um dizer que 
se aproxime do nível do ser e um conhecer que se mantenha conectado com as raízes, com a fonte que é do nível do acontecer e que se recusa à objetificação, mas que não pode ser suprimido sem que a relação com os objetos também seja fechada. Vamos mostrar esse movimento, que é o desafio do pensamento que pretende se libertar do cálculo realizado com compreensões pressupostas e voltar às fontes, às raízes para, a partir desse nível, conquistar a liberdade no pensar, agir e existir, apesar do poder de massificação e nivelamento da cotidianidade. Trata-se de introduzir, ao lado do pensamento que calcula, o pensamento que medita.

Nascemos e crescemos num mundo, numa 'realidade' que nos é transmitida como tradição através da linguagem. Na própria linguagem está guardada a tradição (nossos conhecimentos, regras, possibilidades de ação, etc.) tendencialmente como se fossem objetividades, representações do mundo em si. Esse nível oculta a historicidade, o enraizamento do conhecer, agir e valorar na vida fática e vivida. No dia a dia pensamos, agimos e vivemos desconectados desse nível possibilitador, justamente pelo fato de estarmos encantados e seduzidos pelas coisas com que nos ocupamos, com as distrações, tranquilidades e segurança que elas propiciam. Tendencialmente mantemo-nos no nível dos entes, da cotidianidade e perdemos de vista, esquecemos e até ocultamos de nós o nível do ser. Todo pensamento de Heidegger é, por isso, um movimento do nível dos entes para o sentido do ser. Isso é o que vamos mostrar nas reflexões que seguem.

\section{LINGUAGEM APOFÂNTICA E HERMENÊUTICA}

Um primeiro ponto a ser considerado é que a linguagem acompanha sempre o encontro com o objeto e, além do mais, faz com que o contato com o objeto nunca seja direto, mas sim mediado. Mais do que isso, o objeto é objeto enquanto tal, somente na medida em que há linguagem, uma abertura que doa sentido aos entes. A linguagem é o ambiente no qual já sempre nos movemos e dentro do qual temos acesso aos entes. Ou seja, "sujeitos só podem relacionar-se com objetos no mundo através da mediação da linguagem" (FRANK, in STEIN, 1996, p. 15). E se o sujeito somente tem acesso aos objetos através dela, é imprescindível leva-la em consideração quando se pensa sobre o conhecimento. Se qualquer experiência é feita através da representação linguística, não há experiência pura. Alguém que não tenha conceitos, que não esteja na linguagem, não se pode dizer dele que conheça. Não está na abertura, ou na clareira do ser, na luz da linguagem (cf. HEIDEGGER, 2005). 
Falamos e somos carregados pela linguagem. Ela é como o ambiente em que vivemos, não simplesmente o instrumento que utilizamos para nos comunicar. Nela nos vem a história, a tradição, a realidade, o passado, o projeto e também as possibilidades. Enquanto instrumento ela tem a função de representar os entes, obedecendo a uma estrutura semântica e formal que podemos chamar de horizonte ôntico da linguagem. Mas enquanto 'ambiente', ela sustenta a abertura compreensiva dos entes (o ser), e estamos no horizonte ontológico da linguagem. E, enquanto manifesta os entes, esconde a abertura do ser. Por isso, "o ser não é de forma alguma um conteúdo do pensamento, mas o elemento no qual o pensamento vive como o peixe na água" (Dartigues, 2008, p. 120).

Vattimo $(1996,132)$ acentua que a linguagem não é algo de que dispomos como dispomos dos objetos dentro do mundo. Dispomos dela, sim, enquanto a usamos. Noutro sentido, é muito mais ela que dispõe de nós, delimitando, com as suas estruturas, as experiências possíveis dentro do mundo. As coisas nos comparecem na abertura da linguagem e somente no modo como a linguagem faz os objetos aparecerem. É a linguagem que "proporciona o ser à coisa" (VATTIMO, 1996, p. 136) e "todo falar concreto pressupõe que a linguagem já tenha aberto o mundo e que também a nós nos tenha colocado nele" (VATTIMO, 1996, p. 132).

Stein sugere algumas perguntas: “como conhece alguém quando só conhece através da linguagem? Como deve ser constituído alguém que só conhece através da linguagem?” (1996, p. 15). Embora a linguagem seja em Heidegger uma preocupação explícita a partir dos anos 30, já na década anterior se ocupa com ela, mesmo que brevemente, encaminhando-se para além das concepções lógicas e semânticas tradicionais.

A linguagem atesta a finitude humana. Ela abre o mundo sempre de forma limitada, a partir da lida com os próprios entes, realizada por aquele que fala. É a partir dela que se estrutura a orientação no mundo, com os entes. Ao mesmo tempo, a linguagem não é posse daquele que fala, pois este aprende e apreende, a partir da aprendizagem da fala, um sentido já existente, uma história que o precede e possibilidades implícitas nesta linguagem determinada.

Tratar da linguagem só se pode através da linguagem mesma, o que implica num círculo hermenêutico. Ou seja, "mundo e linguagem formam um único meio universal de sentido, um meio que não pode ser estudado objetivamente a partir de um ponto de observação situado fora dele. A linguagem somente pode ser estudada de maneira circular, já a pressupondo" (KUSCH, 2003, p. 24). Mundo e linguagem não podem ser objetificados, pois estão enredados no círculo da compreensão. Não há como sair dele para dominá-lo. Sair 
significaria sair do horizonte do sentido e, portanto, fechar a abertura na qual se revela o mundo, onde somos-no-mundo. Sem ele sequer teríamos alguma relação com o mundo, estaríamos fora do horizonte de sentido. Somente o ser humano, pela linguagem, é que pode se relacionar com o mundo e somente através do sentido que é carregado pela linguagem podemos conhecer. Podemos dizer que o ser humano é 'formador de mundo' (Cf. HEIDEGGER, 2000) porque ele está na linguagem.

Queremos enfatizar esse movimento duplo da linguagem. Se nosso acesso ao mundo e ao conhecimento só se dão via linguagem; se há sempre um resto que escapa e se o próprio universo da linguagem permanece oculto na palavra que se manifesta, então a linguagem tem algo a ver com o encobrimento daquilo que através dela se manifesta. Ou seja, “a linguagem traz em si um duplo elemento, um elemento lógico-formal que manifesta as coisas na linguagem, e o elemento prático de nossa experiência de mundo anterior à linguagem, mas que não se expressa senão via linguagem, e este elemento é o como e o logos hermenêutico" (STEIN, 1996, p. 20). Mesmo na observação de qualquer fenômeno físico já estamos de alguma forma mergulhados na história e na cultura que nos vem pela linguagem. Não há distanciamento total possível e por isso é preciso interpretar. Para além da lógica e do nível apofântico (manifestativo, expositivo, afirmativo e representacional), a existência concreta e finita sempre conhece interpretando. Mesmo com a dificuldade do reconhecimento por parte da formalidade lógica, “a hermenêutica é esta incômoda verdade [...] nem uma verdade absoluta, nem empírica - é uma verdade que se estabelece dentro das condições humanas do discurso e da linguagem. É por isso que a hermenêutica é, de alguma maneira, a consagração da finitude" (STEIN, 1996, p. 45).

Isso questiona grande parte da tradição que consagrou a verdade como representação e a convicção de que a proposição é verdadeira porque existe um fundamento último empírico ou racional. No universo da hermenêutica, renuncia-se ao fundamento último absoluto e trabalha-se na exposição dos pressupostos sempre atuantes na compreensão, sem pretender esgotá-los. O ser-no-mundo explica e conhece a partir de uma circularidade que não pode ser ultrapassada. Há uma compreensão que sempre se antecipa a qualquer explicação, inclusive para o cientista natural.

O discurso, por isso, apresenta duas dimensões (Cf. STEIN, 2004): a apofântica e a hermenêutica. A primeira está ligada à lógica, à representação e às categorias. É a ontologia da coisa, lógica das categorias, aquela que na tradição metafísica teve lugar de destaque. Heidegger quer mostrar que a essa forma de discurso subjaz outra lógica, vítima do esquecimento metafísico: a hermenêutica. Ela não é suportada pela linguagem que se constrói 
ao estilo da ontologia da coisa, mas manifesta a partir de indícios, de existenciais (cf. 1998). A ontologia fundamental (HEIDEGGER, 1998) é a tentativa para alcançar essa nova lógica, condição de possibilidade da lógica dos entes. É a lógica dos existenciais, marcada pela circularidade hermenêutica e pela diferença ontológica (Cf. HEIDEGGER, 2000). A dimensão hermenêutica é o 'enquanto' que se ocupa do que está velado, do ser do ente, ou seja, do fenômeno no sentido fenomenológico, como dirá Heidegger em Ser e Tempo (Cf. 1998, p. 58).

Considerando essa dupla estrutura da linguagem, a verdade também pode ser repensada. Além da verdade dos enunciados, baseados na representabilidade, na correspondência entre sujeito e objeto, há uma verdade operativa e existencial que precede, enquanto abertura e transcendência, a possibilidade da representação lógica e enunciativa dos entes.

Há, podemos dizer, duas lógicas, dois níveis de linguagem. A primeira é a dos entes, do discurso apofântico, ideal da metafísica, regida pelos princípios da não-contradição e da identidade. Uma linguagem comprometida com a representação. A outra lógica é a lógica do ser, da diferença, da hermenêutica, re-descoberta na recordação do ser. É um pensar sem objetos (entes), mas que mostra o acontecer dos entes e torna possível tal acontecer. É uma lógica caracterizada pela circularidade e diferença (não pela não-contradição e identidade). É uma linguagem que Heidegger busca resgatar "no contexto e por meio do método fenomenológico, onde se trabalha com conceitos que vão se constituindo pela descrição por indícios formais e não com material conceitual pronto, trazido pela linguagem objetificadora da metafísica" (STEIN, 2004, p. 107). Tal linguagem, de cunho hermenêutico, se caracteriza por acenar e aproximar, atitude mais adequada para dizer o que se mantém encoberto e esquecido, aquilo que agora é tarefa do pensamento, o mais importante a ser pensado. Não há como sair da linguagem (que não deixa de ser metafísica, residimos na tradição metafísica), mas é preciso "superar a dimensão metafórica que sempre joga com o modelo dos dois mundos e a relação entre sensível e supra-sensível” (STEIN, 2004, p. 117).

\section{A DUPLA ESTRUTURA DO CONHECIMENTO}


A diferença ontológica representa, no pensamento de Heidegger, a apresentação do nível possibilitador e do possibilitado, a diferença entre ser e ente, onde ser é o elemento a ser (re)apresentado, pois foi vitimado pelo esquecimento na tradição metafísica. Esse esquecimento da diferença aconteceu pelo fato de se tomar o ente como modelo, de termos sido encantados pelos objetos com que lidamos na cotidianidade, e termos ignorado o horizonte dentro do qual os entes, que nos encantam na nossa ocupação com eles, podem aparecer enquanto tais. A metafísica vive deste encanto pelos entes presentes e o estendeu para o ser. $\mathrm{O}$ ente e o ser foram nivelados, desapareceu entre eles a diferença. A metafísica vive na indiferença, na ontologia da coisa, sem acessar a diferença entre ser e ente. $\mathrm{Na}$ metafísica o "manifestar-se que se retrai em favor do aparecer dos entes, passou a ser esquecido, produzindo, dessa forma, um encobrimento, um obnubilamento do espaço em que o todo é compreendido, por exemplo, na dimensão do ser” (STEIN, 2004, p. 86).

Heidegger, para fugir da objetificação e da necessidade de sempre novamente produzir uma teoria para explicar o fenômeno do conhecimento, reconheceu a dimensão prévia, o elemento esquecido na tradição e, com ela, partindo do mundo fático, da finitude, pode propor a superação das dicotomias sujeito e objeto, mente e mundo, sensibilidade e inteligibilidade. Há um sentido que precede a objetivação e objetificação dos entes. Ignorar ou desconhecer essa diferença produz a pretensão de neutralidade científica. A neutralidade não tem sentido quando a diferença é reconhecida. Supera-se, nela, a objetividade e subjetividade separadas. Por isso Heidegger insiste em manter-se no plano ontológico e não no epistemológico.

Tal superação não significa uma negação das diversas teorias que, por pressuporem sempre uma separação, precisam fazer a ponte para unir o sensível ao inteligível. Trata-se do esclarecimento do ambiente prévio onde elas se enraízam. Esse ambiente prévio é um modo de ser, prático, ser-em, ser-no-mundo. Neste caso, "todo acesso à substância do real é substituído por uma atmosfera, pela qual já, desde o início, estamos comunicados com o mundo" (STEIN, 2008, p. 30). Ou seja, não entramos imediatamente em contato com as coisas, mas "temos sempre um certo número de informações preliminares, preconceitos, expectativas a seu respeito, e a linguagem determina, pré-orienta o nosso juízo sobre a realidade" (D'AGOSTINI, 2003, p. 399).

Já estamos sempre na abertura, numa compreensão do ser; acolhemos e transmitimos as vozes do ser (Cf. D’AGOSTINI, 2003, p. 399). Isso elimina a ideia de neutralidade no conhecimento e explica a realidade a partir de uma predisposição na qual já sempre estamos envolvidos. A interpretação se dá de forma circular, pois não podemos sair da compreensão do ser para falar da realidade. As partes são interpretadas com referência à compreensão do todo e vice-versa. Pois "nós 
pertencemos àquele horizonte histórico-linguístico sobre o qual se exercita o nosso interpretar e por isso não podemos jamais ter dele uma compreensão exaustiva" (D'AGOSTINI, 2003, p. 401).

Numa interessante analogia Dastur mostra que não há uma luz ou referência objetiva que venha de fora, mas que temos de nos resignar ao fato de que nossa condição no mundo implica "a manifestação da necessidade de compreensão de um existente que é destinado a residir no mundo e obrigado a acender ele mesmo o fogo que iluminará as paredes da sua prisão" (DASTUR, 2002, p. 112). Essa luz que ilumina as paredes de nossa prisão é a compreensão de ser, sempre finita, guardada na linguagem.

Neste caso, não é preciso um malabarismo teórico para unir o que se separou, pois na 'atmosfera' ou 'luz' que é o mundo já sempre estão ligados o interno e o externo. Heidegger, para superar a dicotomia sujeito-objeto, na qual o conhecimento é objetivado e que se rege pela lógica da necessidade e universalidade, desenvolve

[...] aquilo que seria a sua fenomenologia do conhecimento como fundamento de qualquer teoria do conhecimento. Isto está expresso de diferentes modos na dupla estrutura que vem sugerida no conceito de fenômeno, na distinção entre apofântico e hermenêutico, na diferença entre o dizer e o enunciado, e outros contrapontos que são o objeto principal de Ser e tempo em sua primeira seção (STEIN, 2009, p. 87).

Ernildo Stein apresenta nesta passagem e em diversos outros momentos a convicção de que "a intenção principal que atravessa Ser e Tempo tem a ver com a questão do conhecimento" (STEIN, 2009, p. 85). Afirma ele que

[...] o filósofo, todavia, fora levado, em sua atividade de interpretação dos filósofos gregos, à luz da fenomenologia, à afirmação de uma dupla estrutura do conhecimento que lhe permitira afirmar que antes de uma teoria do conhecimento era preciso uma investigação profunda do modo de ser do mundo em que o ser-aí estava enraizado no ser-em. Esta estrutura primeira deveria ser explicitada mediante o método fenomenológico como sendo o lugar de onde partiria qualquer teoria do conhecimento (STEIN, 2009, p. 85).

Heidegger conquista um novo horizonte, podemos até dizer um novo paradigma, que se contrapõe à tradição e que tem potencial para contribuir na superação das dicotomias e impasses que sofre o problema do conhecimento. Encaminhando-se para o fático, o prático, o pré-teórico, afasta-se da teorização desenraizada. Tem em mira a vida efetiva. O ser-nomundo é concreto, existencial, cotidiano. No nível hermenêutico, do ser, a linguagem se torna indicial, existencial. Além do mais, "quando é introduzido o contraponto entre velamento e desvelamento na questão do método fenomenológico, na forma do enquanto apofântico e do enquanto hermenêutico, o filósofo já define o nível em que irá desenvolver a analítica" (STEIN, 2009, p. 85). O pensamento de Heidegger se move no horizonte hermenêutico e sua linguagem quer ser indicial (trabalhar com indícios formais). 
A analítica existencial ensina que se "deve pressupor uma unidade que vem do sentido. Este sentido já é sempre o mundo dado como totalidade; estou mergulhado neste mundo; há uma unidade que não preciso produzir, pois ela é dada, e a inteligibilidade é produzida pela descrição do meu modo de ser-no-mundo" (STEIN, 2008, p. 36). Nessa totalidade, nesse mundo de sentido já estamos sempre mergulhados desde que aprendemos a ser quem somos. Tendemos a tomar e compreender essa realidade a partir do tempo presente, da presentificação. Dessa forma nos acomodamos sobre o que já sabemos e conquistamos, e nos fechamos ao vir-a-ser, ao inusitado e imprevisível representado pelo futuro. A tradição tende a se fechar sobre si mesma e calcular a partir do que já dispõe, numa fuga do possível e da abertura para o 'acontecimento'.

Por isso, a necessidade de retornar da fuga diante da historicidade, da condição histórica do ente que conhece e do conhecimento. Isso implica na apropriação do passado de forma autêntica, ou seja, conforme as palavras de Rée, "você se apossa de uma herança quando assume o controle dela e lhe dá uma nova abertura para o futuro, não quando simplesmente segue atrás dela guiando-se pelo seu passado" (2000, p. 21).

Já sempre estamos na compreensão e numa tradição e, por isso, não há necessidade de construir pontes ou provas $^{1}$ entre o mundo e a consciência, entre o dentro e fora da consciência. Ou seja, “antes de nos darmos conta nós já compreendemos. O mundo já está compreendido, não há como chegar antes dele e compreendê-lo" (STEIN, 2008, p. 38). Não há a distância que permitiria que um se antecipasse ao outro e lhe oferecesse critérios de verdade ou falsidade. A diferença ontológica substitui a duplicação dos mundos, realizada pela metafísica, caracterizada por diversos binômios e dualismos.

A eliminação das dicotomias e dos mundos paralelos é tornada possível, porque no pensamento de Heidegger ser é tempo e tempo é ser. A dupla estrutura apresentada por Heidegger não é uma duplicação do mundo ou uma dicotomia. A tarefa da filosofia reduz-se ao espaço humano, se dá somente onde existe o homem, pois não há mais ser fora do tempo (cf. STEIN, 2008). O ser é temporalidade, historicidade. Resulta que "se o tempo é o horizonte de toda compreensão, todas as teorias devem converter-se inelutavelmente em formações históricas, e isso afetará o núcleo da razão" (STEIN, 2004, p. 164).

Resta o espaço da faticidade, encarada não mais teórica ou dialeticamente, mas como hermenêutica da faticidade. Intuição e inteligibilidade não se separam, pois "há inteligibilidade na intuição e há intuição no entendimento" (STEIN, 2008, p. 81). Dito de

\footnotetext{
${ }^{1}$ Kant, em uma nota do prefácio à segunda edição de Crítica a Razão Pura, lamenta que tenhamos de "admitir a existências das coisas fora de nós [...] com base apenas na fé [...] (1999, p. 49).
} 
outra forma, não existe uma experiência pura, pois sempre experienciamos num horizonte de sentido prévio. E o entendimento também não é fruto de uma estrutura a priori a-histórica, desligada da experiência concreta, existencial. Aí está claramente a crítica de Heidegger às teorias do conhecimento: o ponto de partida é um ser-no-mundo, o Dasein, sempre limitado e finito. Um ente que existe e que tem a si mesmo como tarefa dentro de uma determinada tradição, com as possibilidades e limitações desta abertura compreensiva, desse projeto. A inteligibilidade e a intuição se constituem mutuamente na lida prática do ser humano com o mundo. Mundo é o resultado dessa interação. Dasein já é sempre no mundo. Na base da consciência está um ser humano concreto e situado, histórico e finito. E a razão tem essa mesma estrutura e não há mais um fundamento necessário e universal.

Com a analítica existencial e a desconstrução da metafísica, Heidegger atinge a questão das teorias do conhecimento. Mostra que

\begin{abstract}
Antes da evidência de qualquer teoria e ponto de partida da 'teoria do conhecimento' e antes de qualquer subjetividade fundante, há uma evidência operando na situação de ser-no-mundo. Esta evidência está encoberta pelo óbvio do cotidiano, da separação consciência-mundo, pelo modelo da relação sujeito-objeto (STEIN, 1990, p. 23).
\end{abstract}

Não há a negação da lógica, da semântica ou do ôntico. Há o desvelamento de uma dimensão que precede a lógica, a semântica, as ciências ônticas, mas cuja tendência é manterse velada nas operações cotidianas. A descrição dessa dimensão compreensiva ou hermenêutica, ligada à visão que Heidegger tem do Dasein, revela o que precede as diversas explicações do conhecimento, as chamadas teorias do conhecimento. E mostra-se a possibilidade de uma fenomenologia do conhecimento, que terá como função "fixar apenas as condições existenciais, estruturais (de transcendência e de ser-no-mundo) para uma teoria do conhecimento" (STEIN, 1990, p. 196). A compreensão do ser e a auto-compreensão antecipam-se ao conhecer, são a condição de possibilidade deste.

Outra forma de mostrar a diferença entre os níveis da dupla estrutura do conhecimento é através do esclarecimento do que seja conhecer e compreender. Segundo Stein estes são dois modos de manifestação do conhecimento em que aparece, por um lado, a dimensão argumentativa e, por outro, a dimensão compreensiva. Neste sentido, "todo pensar é precedido por um compreender prévio e no sentido de um antecipar. E que, portanto, não existe um pensar sem uma estrutura prévia de compreender" (STEIN, 1990, p. 199). Antes do entender e conhecer há o compreender. Somente compreendendo, enquanto ser-no-mundo, entendemos e conhecemos algo. 
O âmbito do enunciativo e argumentativo é aquele com que se ocupam as teorias do conhecimento, enquanto a fenomenologia do conhecimento, sem desprezar esta esfera, lhe acrescenta o elemento da compreensão. Esse elemento da compreensão é o horizonte e abertura finita, interpretativa, histórica, temporal do Dasein, que já sempre compreende o ser e se compreende enquanto compreende o ser. Compreender o ser e compreender a si mesmo significa que o Dasein (ser-aí) está envolvido no círculo hermenêutico: enquanto é a abertura, compreende a si mesmo dentro da mesma abertura de sentido e não pode meter a cabeça para fora e observar à distância para, assim, alcançar objetividade e certeza.

O elemento compreensivo é de caráter transcendental, a priori, mas contingente, temporal, histórico e finito. Ele, ao mesmo tempo, sustenta e participa do conhecer, do acontecer dos entes. Essa é a condição de ser-no-mundo, onde o conhecimento será possibilitado por um "lugar aberto pelo acontecer como a esfera em que é superada a objetificação [...] em que aquilo que é tratado como objeto no discurso enunciativo é levado a revelar-se em seu acontecer" (STEIN, 1990, p. 200).

Em todo conhecer está operando uma pré-compreensão. Antes da classificação, da distinção, das separações e delimitações já está em ação um saber operativo, um saber 'como', uma familiaridade com os entes enquanto utensílios. Antes da teorização sobre os entes, eles já participam de um mundo de sentido, estão numa inter-relação no mundo, servem para algo. A teorização separa e classifica aquilo que já está de alguma forma aberto para o Dasein, précompreensivamente. Esse âmbito de abertura prévia é uma "dimensão pragmático-operativa de um modo de ser do ser humano que exerce a função estruturante e organizadora" (STEIN, 1990, p. 204).

Com o elemento compreensivo da dupla estrutura enfatiza-se que "já-sempre trabalhamos com uma autocompreensão e uma pré-compreensão da totalidade, o que impede que caiamos numa espécie de empirismo aleatório ou de caráter hiperfatual (STEIN, 1990, p. 205). Na pré-compreensão já se está sempre numa espécie de totalidade, na totalidade de sentido, onde as coisas fazem algum sentido, servem para algo, se relacionam umas com as outras no uso. Isso impede que a experiência, como dissemos, seja entendida enquanto captação pura e simples de uma realidade pré-existente. A experiência já é sempre experiência de algo que participa da abertura do sentido. A experiência já se alimenta dum sentido prévio, assim como a pergunta é sempre uma pergunta que já supõe algo previamente compreendido e aberto.

Há este elemento prévio que é condição de possibilidade, entendida esta como modo de ser do Dasein, ser-no-mundo. Não uma condição de possibilidade fora da história, 
necessária e universal, característica de um sujeito supra-empírico. Esse transcendental, condição de possibilidade é, justamente, aquilo que acompanha todo e qualquer objeto que conhecemos. A pré-compreensão evita o unilateralismo das posições teóricas das teorias do conhecimento, pois situa as teorias no seu solo prático primário e fundamental.

Esse sentido prévio não é ao modo dos objetos dentro do mundo, e não pode, por isso, ser exposto, demonstrado, objetivado, definido. Ele sempre escapa, mantém-se velado na representação, é o fenômeno no sentido fenomenológico (cf. HEIDEGGER, 1998). Embora seja condição necessária para o aparecimento dos entes, o ser não tem o modo de ser dos entes e por isso não se permite representação objetiva.

Uma teoria do conhecimento ou qualquer atividade humana tem a marca da condição humana finita. O conhecimento é um modo de ser do ser humano. O homem não pode se libertar do ser-no-mundo ao conhecer, livrar-se das condições fáticas originárias. Seu conhecer está impregnado pelas circunstâncias de tempo e espaço, pela cultura, pela linguagem em que se desenvolve, pelas condições ônticas. Mas, mais do que isso, essas circunstâncias somente são tais por que há Dasein. O sentido do ser (ontológico) é condição de possibilidade do ôntico. Enfim, o ser humano não pode desfazer-se da abertura em que compreende o ser e a si mesmo sem deixar de ser Dasein, sem deixar de ser transcendência. Não há ente que se manifeste sem um horizonte prévio de sentido. As coisas se tornam o que são dentro desse horizonte.

A compreensão, por isso, caracteriza fundamentalmente o ser humano. A compreensão é essa dimensão a priori que não se separa da existência e sim é a realização da própria transcendência (Cf. STEIN, 2004, p. 213). A dimensão prévia, o transcendental, está ligado intimamente à existência, não pode ser separado do modo fundamental de ser no mundo do Dasein, participa da finitude da abertura do sentido do ser. Se trata de um transcendental nãoclássico, que não tem pretensões de universalidade e necessidade e não obedece às leis da lógica metafísica. O próprio transcendental tem o modo de ser do ente que conhece, ou seja, é temporal e no-mundo.

A ontologia fundamental que Heidegger desenvolve se move neste horizonte da dupla estrutura. Não seria possível sem o reconhecimento da diferença ontológica. Como diz Stein,

A função mais importante da hermenêutica da faticidade, da analítica existencial ou da ontologia fundamental será introduzir uma nova maneira de falar das coisas e do ser humano, desde o pressuposto da compreensão do ser. Com isso se supera a objetificação das coisas e do ser humano e se estabelece um modo de dar-se, num processo compreensivo primeiro e fundamental (2004, p. 213). 
$\mathrm{O}$ esquema sujeito-objeto, o dualismo que caracteriza as teorias do conhecimento pretende-se poder ser superado na recuperação da diferença ontológica. Introduz-se um novo modo de falar do ser humano, não mais ao modo dos demais entes presentes e reificados. A temporalidade no lugar do tempo cronológico, tempo dos objetos, é que permite essa fuga do fechamento no presente. O ser humano tem um modo próprio de ser, ele é ser-no-mundo, existe, e, além disso, é formador de mundo (cf. HEIDEGGER, 2006). O ser humano compreende, é a razão pela qual se pode falar do sentido do ser. O modo de ser do ser humano é que é a condição de possibilidade de qualquer conhecimento objetivo (Cf. STEIN, 2004, p. 221). Na medida em que o ser humano se compreende em seu ser, ele é posto como lugar da diferença ontológica. Neste posto jamais pode ser objetivado, pois sua faticidade não pode ser superada, ele não pode sair dela, nem ir para além ou para trás. Ele não é uma substância ou essência, como se pretende dos outros entes. Não cabe na presença e linearidade do tempo. A realidade humana terá de, por isso, ser descrita com outra linguagem, não mais metafísica e dualista.

\section{CONSIDERAÇÕES FINAIS}

Há, segundo o pensar de Heidegger, dois níveis no conhecer: um, ligado à compreensão, que antecipa o sentido e acompanha o outro que é apofântico. O conhecer da compreensão foge à objetividade ôntica e, por isso, nunca poderá ser plenamente explicitado, manterá sempre um resto que não entra no cálculo. Não há como objetificar e nem objetivar esse espaço prévio, da pré-compreensão e isso favorece e "defende o próprio processo de conhecimento dos objetos de uma total objetificação" (STEIN, 2004, p. 222). Como o fundo não pode ser objetificado e nem objetivado, o ente que se manifesta sobre esse fundo fica protegido contra as pretensões de enquadramento total. Mantém-se, neste caso, sob os enunciados fáticos a condição do acontecer dos entes, a pré-compreensão. Qualquer fundamentação, qualquer discurso sobre os entes já está enraizado e é comandado pela dimensão prévia e antecipadora da pré-compreensão. Os entes e suas determinações são posteriores, sustentados por um horizonte de outro nível, por um transcendental que abre o ser humano enquanto Dasein para a transcendência. Na transcendência e sustentado por ela, o ser humano conhece, explica, fala sobre os objetos e os determina. Mas a transcendência não se esgota ou deixa encapsular na fala sobre os objetos possibilitados por ela.

Somente temos os conhecimentos das diversas áreas ônticas, mesmo das mais exatas e previsíveis, porque antes compreendemos o ser. Neste sentido, o ontológico preside e precede 
o ôntico. O ôntico não é neutro ou natural, mas está organizado a partir do sentido. Ou seja, "somente podemos explorar o caráter entitativo e natural das coisas porque elas já estão presas na rede de compreensão do ser" (STEIN, 2004, p. 233). E, de forma sintética e clara, "não é o mundo natural que é o organizador das nossas crenças pela causalidade, mas é o sentido que nós projetamos, antecipamos na pré-compreensão, enquanto seres no mundo que se torna o organizador do mundo natural" (STEIN, 2004, 234). A ciência, portanto, pressupõe sempre algo, embora pretenda neutralidade e objetividade. No conhecer não lida simplesmente com um objeto, mas tem sempre um sentido que antecipa o objeto no seu ser, o delimita e circunscreve. Há uma rede de relações dentro da qual o ente é algo enquanto algo, isso ou aquilo.

Mas o nível da pré-compreensão, compreensão do ser, desenvolvido com a fenomenologia hermenêutica, não pretende ser uma descrição ou acesso melhor aos entes. A ciência, o ôntico, deve continuar seu trabalho, pois somente ela tem condições de descrever os entes. A filosofia atém-se ao ser dos entes e ao sentido do ser. Dessa forma, "sem desprezar a necessidade que a ciência tem de objetificar, a hermenêutica abre um novo espaço, aquele desde sempre pressuposto pela objetificação e que foi explicitado pelas análises da facticidade que Heidegger realizou" (STEIN, 2004, p. 241).

Ao pensar cabe exercitar a compreensão, movimentar-se dos entes para o ser. As ciências ônticas, campos de investigação com objeto específico, delimitado e acessado metodologicamente, hão de continuar se ocupando dos seus objetos. Mas, junto com essa atenção aos objetos (do nível da linguagem e do conhecimento explicativos e cotidianos), a atenção ao sentido do ser, na manutenção da atenção na abertura, produz-se uma liberdade e disponibilidade para a experiência enquanto tal, sem enquadramentos e cálculos prévios necessários e generalizantes (nível da compreensão, da hermenêutica). O trabalho de pensar há de acompanhar a relação com os entes para que não nos percamos nos encantos e nos fixemos nas certezas do cálculo. Os dois movimentos são importantes, na medida em que, envolvidos com os entes, o sentido do ser impede que nos calcifiquemos e mantém nossa capacidade de ver além e nossa criatividade. A proximidade com o inaugural permite a possibilidade de reinaugurar sempre novamente as representações da realidade.

A introdução ou a lembrança do nível esquecido (embora primário e fundante) permite compreender e experimentar que já sempre pertencemos, somos, temos familiaridade com uma tradição. Não somos neutros ou objetivos, mas já sempre somos e compreendemos a partir de um pré, de um fundo compreensivo guardado na linguagem, na tradição e que herdamos quando aprendemos a falar e ser dentro de uma determinada cultura ou abertura. E 
estamos, por isso, numa circularidade da qual não podemos escapar, mas da qual podemos sempre nos apropriar e assumir. Não podemos eliminar nossos conceitos (que são sempre de alguma forma pré-conceitos, pois se antecipam às coisas), pois são eles que nos dotam de uma visão, uma compreensão, um ser determinado. O nível originário resgata a compreensão das realidades e determinações como possibilidades realizadas e tendencialmente cristalizadas na tradição.

$\mathrm{Na}$ cotidianidade, no envolvimento com o mundo cultural e com os objetos, normalmente vemos sem ver aquilo que nos permite ver, pensamos sem pensar isso que nos permite pensar, conhecemos sem conhecer isso que nos permite conhecer, ou seja, do ontológico como condição do ôntico. Embora falemos, utilizemos a linguagem, o fazemos de modo automático e irrefletido, pois nos mantemos presos na informação, na representação, sem acesso ao acontecer do que se dá na representação e na informação e nem atentamos para o que se retrai no conceito, na lógica e na gramática. Por isso a importância da abertura que o nível ontológico representa na existência humana, a partir do qual podemos experimentar o próprio experimentar, liberando a abertura enquanto abertura (sentido do ser) e propiciando a disposição para o diálogo ao invés da manutenção ininterrupta do monólogo.

\title{
DOUBLE STRUCTURE OF LANGUAGE AND KNOWLEDGE IN HEIDEGGER
}

\begin{abstract}
ABSTRATC
The text presents language and knowledge from two levels: the level of things and the level of being. Every day we move into an understanding of language and knowledge based on objetification or reification. We lose the connection to the soil and the preconceptual roots where our ventures settle. Martin Heidegger's thought can be a warning to the danger by reducing everything to thing, to object, because so we lose the ability to think, to maintain connection to he originary and thereby become dependent of the things we create and deal with every day. We will present and distinguish these two levels of language and knowledge in Heidegger's thought and the interpretation of Ernildo Stein.
\end{abstract}

Keywords: Language, knowledge, Heidegger.

\section{DUPLA ESTRUCTURA DEL LENGUAJE Y DEL CONOCIMIENTO EN HEIDEGGER}

\section{RESUMEN}

El texto presenta el lenguge y el conocimento a partir de dos niveles: el nivel de los entes y el nivel del ser. Cotidianamente nos movemos en una comprensión del lenguaje y del conocimiento basado en la entificación o coisificación. Perdemos la conexión con el solo y las 
raíces pre-conceituales donde nuestros emprendimentos se asentan. El pensamiento de Martin Heidegger puede ser un alerta para el perigo de que al reducir todo a ente, a objeto, perdemos la capacidad de pensar, de mantener conexión con el originario y, con eso, nos tornamos dependientes de las cosas que creamos y con que lidamos cotidianamente. Vamos presentar y distinguir estos dos niveles del lenguaje y del conocimiento a partir del pensamiento de Heidegger y de la interpretación de Ernildo Stein

Palabras Clave: Lenguaje, conocimiento, Heidegger.

\section{REFERÊNCIAS}

D’AGOSTINI, Franca. Analíticos e Continentais. São Leopoldo - RS: Editora Unisinos, 2003.

DARTIGUES, André. O que é fenomenologia. São Paulo: Centauro, 2008.

DASTUR, Françoise. A morte - ensaio sobre a finitude. Trad. Maria T. Pontes. Rio de Janeiro: DIFEL, 2002.

HEIDEGGER, Martin. Ser y Tiempo. Chile: Editorial Universitária, 1998.

. O que é Metafísica. In: Conferências e Escritos Filosóficos. São Paulo: Editora Nova Cultural, 2000.

Carta sobre o humanismo. São Paulo: Centauro, 2005.

Conceitos Fundamentais da Metafísica: mundo, finitude e solidão. Rio de Janeiro:

Forense Universitária, 2006.

KANT, Immanuel. Crítica da Razão Pura. São Paulo: Editora Nova Cultural, 1999.

KUSCH, Martin. Linguagem com cálculo versus linguagem como meio universal. São Leopoldo: Editora UNISINOS, 2003.

RÉE, Jonathan. Heidegger. São Paulo: Editora UNESP, 2000.

STEIN, Ernildo. Seis estudos sobre Ser e Tempo (Martin Heidegger). $2^{\mathrm{a}}$ Ed. Petrópolis: Vozes, 1990.

Aproximações sobre hermenêutica. Porto Alegre: EDIPUCRS, 1996.

. Exercícios de Fenomenologia - limites de um paradigma. Ijuí: Editora Unijuí, 2004.

. Racionalidade e Existência - O Ambiente Hermenêutico e as Ciências Humanas. $2^{\mathrm{a}}$

Ed. Ijuí: Unijuí, 2008.

Antropologia Filosófica - questões epistemológicas. Ijuí: Unijuí, 2009. 
VATTIMO, Gianni. Introdução a Heidegger. Lisboa: Instituto Piaget, 1996.

\section{Sobre o autor}

Cezar Luíz Seibt é Doutor em filosofia, docente na pós-graduação em Educação e na pósgraduação em Psicologia. Endereço eletrônico: celuse@ufpa.br 